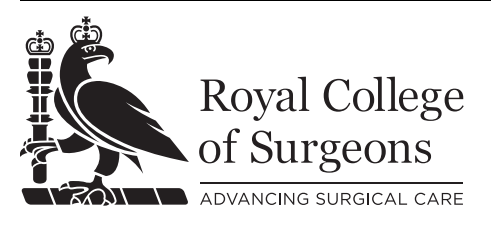

\section{BARIATRIC SURGERY}

\section{Mid-term bariatric surgery outcomes for obese patients: does weight matter?}

\author{
N Samuel, Q Jalal, A Gupta, FAK Mazari, P Vasas, S Balachandra \\ Department of Upper Gastrointestinal and Bariatric Surgery, Doncaster and Bassetlaw \\ Teaching Hospital NHS Trust, Doncaster, South Yorkshire, UK
}

\section{ABSTRACT}

INTRODUCTION Studies have attempted to identify prognostic indicators for successful outcomes following bariatric surgery for obesity. The aim of this study was to determine whether the degree of obesity affects outcomes in patients who are morbidly obese (basal metabolic index, BMI, 40-49.9 kg/m²), super-obese (BMI 50-59.9 kg/m²) and super-super-obese (BMI greater than $60 \mathrm{~kg} / \mathrm{m}^{2}$ ) undergoing restrictive or malabsorptive bypass procedures.

MATERIAL AND METHODS Retrospective analysis of a prospectively maintained database was undertaken to include all consecutive laparoscopic adjustable gastric bands (LAGB), laparoscopic sleeve gastrectomies (LSG) and laparoscopic Roux-en-Y gastric bypass (LRYGB) procedures since 2010. Patients with at least two years of follow-up were included. At each visit, the patient's weight, BMI, excess weight loss and comorbidity status were recorded.

RESULTS A total of 353 patients (75\% women) were included in the analysis; 65 (18.4\%) underwent LAGB; 70 (19.8\%) LSG and $218(61.8 \%)$ LRYGB. At presentation, the median BMI for the morbidly obese sub-group was $47.2 \mathrm{~kg} / \mathrm{m}^{2}$ for LAGB, 46.4 $\mathrm{kg} / \mathrm{m}^{2}$ for LSG and $46.6 \mathrm{~kg} / \mathrm{m}^{2}$ for LRYGB $(P=0.625)$; for the super-obese sub-group it was $53.2 \mathrm{~kg} / \mathrm{m}^{2}$ for LAGB, $52.9 \mathrm{~kg} / \mathrm{m}^{2}$ for LSG and $52.4 \mathrm{~kg} / \mathrm{m}^{2}$ for LRYGB $(P=0.481)$; and for the super-super-obese sub-group $66.9 \mathrm{~kg} / \mathrm{m}^{2}$ for (LAGB, $66.7 \mathrm{~kg} / \mathrm{m}^{2}$ for LSG and $61.5 \mathrm{~kg} / \mathrm{m}^{2}$ for LRYGB $(P=0.169)$.

Percentage of excess weight loss at the end of two years was significantly higher in the morbidly obese and super-morbidly obese sub-groups undergoing LRYGB (median $68.5 \%$ and $69.5 \%$, respectively; $P<0.001$ ) than in the sub-groups undergoing LAGB and LSG. This was also reflected in the reduction of BMI achieved with bypass in the two sub-groups $(P<0.001)$. Complete diabetes remission was significantly higher in the morbidly obese and super-morbidly obese sub-groups undergoing LRYGB treatment $(P<0.05)$. Sleep apnoea, asthma and exercise tolerance had significantly improved in the super-morbidly obese undergoing LRYGB $(P<0.05)$. There was no significant difference between the three treatment groups in remission of hypertension; dyslipidaemia; gastro-oesophageal reflux disease and depression in all three BMI sub-groups.

CONCLUSION The mid-term results for weight loss and resolution of obesity-related comorbidities is best achieved in super-obese patients undergoing LRYGB, without any significant increase in complications with this procedure as compared with LAGB and LSG.

\section{KEYWORDS}

Obesity - Basal metabolic index - BMI - Bariatric surgery

Accepted 9 June 2019

CORRESPONDENCE TO

Nehemiah Samuel, E: samdoc27@yahoo.com

\section{Introduction}

The benefits of bariatric surgery in morbidly obese individuals are well established. As the obesity epidemic spreads, more and more patients seek and qualify to have bariatric procedures to reap the benefits of weight loss, for the treatment of obesity-associated comorbidities and to improve their quality of life. Patients want the best outcome from such life-changing surgery. Likewise healthcare professionals wish to offer the appropriate bariatric procedure for their patients to achieve best possible effects. The prognostic indicators following bariatric surgery is an area of ongoing research. Among such indicators, weight and BMI have often been used as surrogate markers to decide on the type of bariatric procedure likely to suit a patient. The aim of this study was to evaluate this practice and to determine whether degree of obesity affects outcomes in patients undergoing the restrictive (gastric band, sleeve gastrectomy) procedures and the mal-absorptive (gastric bypass) procedures, which are popular and commonly undertaken standardised procedures in the treatment of morbid obesity and associated metabolic conditions. ${ }^{1,2}$ 


\section{Material and methods}

Data were prospectively collected from the departmental database, recording routine perioperative assessments and follow-up findings. All consecutive patients who presented to a single bariatric centre and undergoing bariatric procedures over a period of four years (2010-2014) were included in this study. This ensured at least a two-year (mid-term) postoperative follow-up for included patients.

Inclusion criteria were morbidly obese individuals who qualified for a tier 4 surgical intervention offered within the NHS and who underwent a procedure of their own choice after receiving multidisciplinary team assessment by a bariatric dietician, physician, surgeon, anaesthetist, clinical nurse specialist and psychologist, including a 60minute seminar with a video presentation about the surgical procedures offered (band, sleeve and bypass) before making an informed decision on the type of surgery they wished to proceed with.

Exclusion criteria were revisional bariatric procedures and in whom the multidisciplinary team found contraindications for the patient to make their own choice regarding the type of bariatric procedure they wished to receive. This was the case for patients with previous surgical history (laparotomies, large incisional hernias, surgery for Crohn's disease) or significant medical comorbidities (extreme weight, high anaesthetic risk) and those who were noncompliant with follow-up.

\section{Bariatric procedures}

Laparoscopic Roux-en-Y gastric bypass (LRYGB) was performed in the conventional way, using a 20-30-ml lesser curve-based gastric pouch and anastomosing it to a jejunal segment by the handsewn technique, bypassing 100-150 $\mathrm{cm}$ (30-50 cm biliopancreatic limb and 70-100 cm Roux limb) distal to the Treitz ligament (duodenojejunal flexure). Both the mesenteric and the Petersen space were closed by a non-absorbable suture material.

Laparoscopic sleeve gastrectomy (LSG) was performed by using a $38 \mathrm{~F}$ bougie and Ethicon Echelon ${ }^{\mathrm{TM}} 60-\mathrm{mm}$ stapler, two green staplers at the aboral end of the sleeve and purple staplers afterwards. GORE ${ }^{\circledR}$ Seamguard ${ }^{\circledR}$ Bioabsorbable Staple Line Reinforcement (W. L. Gore \& Associates, Flagstaff, AZ) was applied for most of the procedures. For the adjustable gastric band insertion, the pars flaccida technique was employed and the Lap-Band $\mathrm{AP}^{\circledR}$ Adjustable Gastric Banding System (Allergan, Inc.) was used. Patients were generally discharged home $36-48$ hours post-procedure, after which they received routine follow-up at 1 week, 6 weeks, 3, 6, 12 and 24 months.

\section{Outcomes}

The primary outcome of this study was the loss of excess body weight and hence the basal metabolic index (BMI) achieved at the end of two years. Secondary outcomes such as perioperative morbidity (anastomotic leak rates, bleeding, readmission and reoperation rates) and the mid-term remission of obesity-related comorbidities such as diabetes and sleep apnoea were also assessed at the end of two years. For diabetes remission, the American Diabetes Association's guidelines were followed. ${ }^{3}$ The definition of remission of obstructive sleep apnoea was when the 24hour sleep study confirmed the absence of sleep apnoea and it was deemed safe to stop using the CPAP machine. ${ }^{4}$

\section{Statistical analysis}

Data were recorded on to a dedicated database using Microsoft Excel. Continuous data were first tested for normality using histograms. Based on distribution testing results, the continuous variables were presented as median with interquartile range (IQR) and analysed using the Kruskal-Wallis analysis of variance test for unrelated samples. Categorical data were analysed using the chi-square test. Statistical analysis was done using SPSS $^{\circledR}$ version 21.0.

\section{Results}

A total of 353 patients were included in this study. Patients underwent a procedure of their choice, either LAGB ( $n=$ $65)$, LSG $(n=70)$ or LRYGB $(n=218)$. These patients were further subcategorised into morbidly obese (BMI 40-49.9 $\left.\mathrm{kg} / \mathrm{m}^{2}\right)$, super-obese $\left(50-59.9 \mathrm{~kg} / \mathrm{m}^{2}\right)$ and super-superobese $\left(>60 \mathrm{~kg} / \mathrm{m}^{2}\right) 5$. Baseline demographics were comparable between the three groups, with the majority being women, in the morbidly obese and super-obese subcategories (Tables 1 and 2).

The primary outcome of excess body weight loss was significantly higher for the morbidly obese and super obese categories undergoing bypass procedures and hence the BMI achieved at the end of two years was significantly lower in the same categories of patients (Table 3). There were no significant differences between the intervention groups and the BMI subgroups in the secondary outcomes of perioperative morbidity (anastomotic leak rates, bleeding, reoperation rates) and 30-day readmission rates (Table 4); however, mid-term remission of obesity-related comorbidities such as diabetes, sleep apnoea, asthma and improved exercise tolerance were significantly better in the super-obese subgroup of patients undergoing the LRYGB procedure (Table 5).

\section{Discussion}

The choice of bariatric procedure offered to patients is no longer dependent on the surgeon's experience or preferences to perform a specific procedure. It is based on a multidisciplinary team approach towards recommending individual patient treatment, reinforced by counselling and discussions, to facilitate informed consent by weighing the risks and benefits of specific techniques, the likely or anticipated outcomes, the context in which the procedures are offered (such as for weight reduction purposes) and its accompanying health benefits and/or for primary metabolic benefits, and also considering patient-related limiting factors such as previous laparotomy, extreme weight, multiple or significant comorbidities that are expected to proportionally increase perioperative morbidity. The bariatric unit at Doncaster Royal Infirmary has, since its inception 


\begin{tabular}{|c|c|c|c|c|}
\hline & LAGB $(n=65)$ & LSG $(n=70)$ & LRYGB $(n=218)$ & $P$-value ${ }^{a}$ \\
\hline \multicolumn{5}{|l|}{ BMI subcategories ${ }^{b} n,(\%)$ : } \\
\hline MO $(40-49.9$ kg/m²) & $23(35.3)$ & $31(44.2 \%)$ & $104(47.7 \%)$ & 0.625 \\
\hline SO $\left(50-59.9 \mathrm{~kg} / \mathrm{m}^{2}\right)$ & $38(58.4)$ & $33(47.1 \%)$ & $101(46.3 \%)$ & 0.481 \\
\hline $\mathrm{SSO}\left(>60 \mathrm{~kg} / \mathrm{m}^{2}\right)$ & $4(6.1)$ & $6(8.5 \%)$ & $13(5.9 \%)$ & 0.169 \\
\hline \multicolumn{5}{|l|}{ Female gender ${ }^{b} n,(\%):$} \\
\hline Morbidly obese & $18(81.8)$ & $18(60 \%)$ & $83(80.6 \%)$ & 0.053 \\
\hline Super-obese & $25(65.8)$ & $23(69.7 \%)$ & $78(77.2 \%)$ & 0.349 \\
\hline Super-super-obese & $1(25)$ & $4(66.7 \%)$ & $12(92.3 \%)$ & 0.025 \\
\hline \multicolumn{5}{|l|}{ Age (years), median (IQR): } \\
\hline Morbidly obese & $52.6(42.5-59.8)$ & $41.9(33.7-52.9)$ & $43.8(36.8-50.9)$ & 0.070 \\
\hline Super-obese & $52.0(41.2-61.6)$ & $46.8(39.9-55.5)$ & $41.9(32.1-47.3)$ & 0.005 \\
\hline Super-super-obese & $43.4(29.3-53.6)$ & $40.2(32-49.4)$ & $39.7(26.3-49)$ & 0.983 \\
\hline \multicolumn{5}{|c|}{ Initial weight (kg), median (IQR): } \\
\hline Morbidly obese & $123.5(116.1-133.6)$ & $136.4(121.9-154)$ & $126.9(118.9-138.6)$ & 0.074 \\
\hline Super-obese & $147.1(136.6-165.8)$ & $142.5(137.4-155.1)$ & $144.8(135-156.2)$ & 0.621 \\
\hline Super-super-obese & $203.7(181.7-221.8)$ & $192.1(159.9-214.9)$ & $163.2(153.3-194.3)$ & 0.438 \\
\hline \multicolumn{5}{|c|}{ Excess body weight (kg), median (IQR): } \\
\hline Morbidly obese & $58.2(54.4-63.7)$ & $64.1(54.8-72.5)$ & $59(54.1-66.4)$ & 0.213 \\
\hline Super-obese & $76.7(71.9-88.9)$ & $73.6(69.9-83.9)$ & $77.4(69.9-83.9)$ & 0.835 \\
\hline Super-super-obese & $127.5(116-137.1)$ & $119.2(98.6-137.1)$ & $96.7(90.4-120.3)$ & 0.053 \\
\hline \multicolumn{5}{|c|}{ BMI $\left(\mathrm{kg} / \mathrm{m}^{2}\right)$, median (IQR): } \\
\hline Morbidly obese & $47.2(46.3-48.3)$ & $46.4(44.5-48.3)$ & $46.6(44.8-48.3)$ & 0.625 \\
\hline Super-obese & $53.2(51.6-55.2)$ & $52.9(50.7-55.5)$ & $52.4(51.1-54.7)$ & 0.481 \\
\hline Super-uper-obese & $66.9(65.5-69.2)$ & $66.7(62.1-69.6)$ & $61.5(60.6-65.6)$ & 0.169 \\
\hline \multicolumn{5}{|c|}{$\begin{array}{l}\text { a } P \text {-values calculated using Kruskal-Wallis analysis of variance test across groups of continuous variables. } \\
\text { b } \text {-values estimated using chi-square test across groups of categorical variables. } \\
\text { BMI, basal metabolic index; IQR, interquartile range; LAGB, laparoscopic adjustable gastric bands; LRYGB, Laparoscopic Roux-en-Y gastric } \\
\text { bypass; LSG, laparoscopic sleeve gastrectomy. }\end{array}$} \\
\hline
\end{tabular}

in 2010, followed this unique approach of patients making their own informed choices regarding the procedure that best suits them, based on all the above factors. This in turn has created a growing cohort of patients who have selfselected themselves into one of the bariatric procedure groups and their follow-up data have offered some resourceful insight into subsequent weight loss and metabolic benefits in a self-selected group undergoing different standardised interventions, as well as trends and patient preferences in their choice of weight reduction surgery. ${ }^{6}$

Our results demonstrate that the total weight loss, percentage excess weight loss and hence the change in BMI postoperatively was significantly greater in the LRYGB group in comparison with the LSG and LAGB groups over the mid-term follow-up, which is comparable to results published in the literature. ${ }^{1,7-10}$ The outcomes from randomised controlled trials such as the UK based By-Band- sleeve study ${ }^{11}$ and the German BariSurg trial ${ }^{12}$ are eagerly awaited and may establish the superiority of one procedure over the others in the short and long term by comparing their primary outcomes of postoperative excess weight loss over time.

While the success of bariatric surgery in the form of excess weight loss as a percentage of initial weight has long been debated as arbitrary, simplistic and not reflective of patient's targeted goals and expectations, ${ }^{13,14}$ nevertheless it is an objectively measurable and accepted criterion to measure the success rate of bariatric procedures. In pursuit of this success, considerable work has been done in understanding mechanisms involved in weight loss after bariatric procedures and work continues in refining and tailoring techniques to individual patients anticipated outcomes. Discussion of mechanisms of weight loss from different techniques is beyond the scope of this study. What is 
Table 2 Baseline comorbidities for study participants.

\begin{tabular}{|c|c|c|c|c|}
\hline & LAGB $(n=65)$ & LSG $(n=70)$ & LRYGB $(n=218)$ & $P$-value ${ }^{\text {a }}$ \\
\hline \multicolumn{5}{|l|}{ Diabetes $^{\mathrm{b}} n,(\%)$ : } \\
\hline Morbidly obese $\left(40-49.9 \mathrm{~kg} / \mathrm{m}^{2}\right)$ & $13(59.1)$ & $6(20)$ & $50(48.5)$ & 0.101 \\
\hline Super-obese (50-59.9kg/m²) & $13(34.2)$ & $9(27.2)$ & $26(25.7)$ & 0.908 \\
\hline Super-super-obese $(>60$ kg/m²) & $1(25)$ & $4(66.6)$ & $4(30.7)$ & 0.185 \\
\hline \multicolumn{5}{|l|}{ Obstructive sleep apnoea ${ }^{\mathrm{b}} n,(\%)$ : } \\
\hline Morbidly obese & $2(9.1)$ & $7(23.3)$ & $17(16.5)$ & 0.395 \\
\hline Super-obese & $9(23.7)$ & $7(21.2)$ & $13(12.9)$ & 0.240 \\
\hline Super-super-obese & $1(25)$ & 0 & $1(7.7)$ & 0.382 \\
\hline \multicolumn{5}{|l|}{ Hypertension ${ }^{\mathrm{b}} n,(\%)$ : } \\
\hline Morbidly obese & $15(68.2)$ & $7(23.3)$ & $51(49.5)$ & 0.004 \\
\hline Super-obese & $18(47.4)$ & $16(48.5)$ & $32(31.7)$ & 0.109 \\
\hline Super-super-obese & $1(25)$ & $2(33.3)$ & $4(30.8)$ & 0.961 \\
\hline \multicolumn{5}{|l|}{ Dyslipidaemia ${ }^{\mathrm{b}} n,(\%)$ : } \\
\hline Morbidly obese & $11(50)$ & $7(23.3)$ & $38(36.9)$ & 0.189 \\
\hline Super-obese & $16(42.1)$ & $10(30.3)$ & $21(20.8)$ & 0.039 \\
\hline Super-super-obese & 0 & $2(33.3)$ & $4(30.8)$ & 0.423 \\
\hline \multicolumn{5}{|l|}{ Asthma ${ }^{\mathrm{b}} n,(\%):$} \\
\hline Morbidly obese & $1(4.5)$ & $7(23.3)$ & $19(18.4)$ & 0.188 \\
\hline Super-obese & $6(15.8)$ & $10(30.3)$ & $19(18.8)$ & 0.266 \\
\hline Super-super-obese & 0 & $1(16.7)$ & $1(7.7)$ & 0.645 \\
\hline \multicolumn{5}{|c|}{ Gastro-oesophageal reflux disease ${ }^{b} n,(\%)$ : } \\
\hline Morbidly obese & $1(4.5)$ & $3(10)$ & $24(23.3)$ & 0.051 \\
\hline Super-obese & $9(23.7)$ & $6(18.2)$ & $12(11.9)$ & 0.213 \\
\hline Super-super-obese & $1(25)$ & $2(33.3)$ & $1(7.7)$ & 0.355 \\
\hline \multicolumn{5}{|l|}{ Depression $n,(\%)$ : } \\
\hline Morbidly obese & $4(18.2)$ & $12(40)$ & $30(29.1)$ & 0.230 \\
\hline Super-obese & $10(26.3)$ & $10(30.3)$ & $29(28.7)$ & 0.902 \\
\hline Super-super-obese & 0 & $1(16.7)$ & $2(15.4)$ & 0.693 \\
\hline \multicolumn{5}{|c|}{ Exercise tolerance (flights of stairs), median (IQR): } \\
\hline Morbidly obese & $1(0.5-1)$ & $1(0.5-3)$ & $1(1-3)$ & 0.197 \\
\hline Super-obese & $1(0.5-1)$ & $1(0.5-1)$ & $1(0.5-3)$ & 0.040 \\
\hline Super-super-obese & $0.75(0.125-1)$ & $0.75(0.375-1)$ & $0.5(0.5-1)$ & 0.986 \\
\hline
\end{tabular}

pertinent to this paper and has also been the focus of recent studies is the recognition of predictors of outcomes following bariatric procedures. ${ }^{15-18}$

The mid- to long-term results for weight loss and resolution of comorbidities in our study was best achieved in the LRYGB super-obese subgroup in comparison with the morbidly obese, super-obese and super-super-obese subgroups undergoing LSG and LAGB procedures and the supersuper-obese subgroup undergoing LRYGB. The superior weight loss and metabolic benefit results recorded with LRYGB in the super-obese cohort of patients in this study is unique and worthy of note. A similar large $(n=4935)$ comparative study compared LRYGB and LSG across BMI subcategories of less than 45,50 and $55 \mathrm{~kg} / \mathrm{m}^{2}{ }^{29}$ Their results 


\begin{tabular}{|c|c|c|c|c|}
\hline Outcome at end of two years & LAGB $(n=65)$ & LSG $(n=70)$ & LRYGB $(n=218)$ & $P$-value \\
\hline \multicolumn{5}{|l|}{ Weight (kg), median, (IQR): } \\
\hline Morbidly obese $\left(40-49.9 \mathrm{~kg} / \mathrm{m}^{2}\right)$ & $108.2(99.2-116)$ & $114.9(97.8-123.4)$ & $90.4(79.2-96)$ & $<0.001$ \\
\hline Super-obese $\left(50-59.9 \mathrm{~kg} / \mathrm{m}^{2}\right)$ & $120.5(101.9-141)$ & $116(102.8-126.3)$ & $93.7(80-107.8)$ & $<0.001$ \\
\hline Super-super-obese $\left(>60 \mathrm{~kg} / \mathrm{m}^{2}\right)$ & 163.3 & 127.4 & $115.6(107.7-147.2)$ & 0.264 \\
\hline \multicolumn{5}{|c|}{ Percentage excess body weight loss, median, (IQR): } \\
\hline Morbidly obese & $34.8(19-50.3)$ & $52.6(27.7-74)$ & $68.5(58.9-80.4)$ & $<0.001$ \\
\hline Super-obese & $35.4(19.6-52.9)$ & $39.2(23.2-54.9)$ & $69.5(57.2-85.2)$ & $<0.001$ \\
\hline Super-super-obese & 36.5 & 58.5 & $45.5(41.7-58.9)$ & 0.290 \\
\hline \multicolumn{5}{|l|}{ BMI $\left(\mathrm{kg} / \mathrm{m}^{2}\right)$, median (IQR): } \\
\hline Morbidly obese & $40.7(36.7-43.5)$ & $40.7(36.7-43.5)$ & $31.5(29.2-34.4)$ & $<0.001$ \\
\hline Super-obese & $42.5(40.4-47.3)$ & $42.5(40.4-47.3)$ & $34.5(29.7-37.5)$ & $<0.001$ \\
\hline Super-super-obese & 51.4 & 51.4 & 49.6 & 0.264 \\
\hline
\end{tabular}

somewhat concur with ours in that there was no significant difference in the percentage of excess weight loss following LRYGB and LSG in the lower $\left(<45 \mathrm{~kg} / \mathrm{m}^{2}\right)$ BMI cohorts, whereas there was a greater percentage of excess weight loss with LRYGB in the higher $\left(>45 \mathrm{~kg} / \mathrm{m}^{2}\right)$ BMI cohort. Although the BMI subcategorisation in the two studies are

\begin{tabular}{|c|c|c|c|c|c|c|c|}
\hline & \multicolumn{2}{|c|}{ LAGB $(n=65)$} & \multicolumn{2}{|c|}{ LSG $(n=70)$} & \multicolumn{2}{|c|}{ LRYGB $(n=218)$} & \multirow[t]{2}{*}{$P$-value ${ }^{\text {a }}$} \\
\hline & $n(\%)$ & Complication & $n(\%)$ & Complication & $n(\%)$ & Complication & \\
\hline 30-day complication rate: & & & & & & & 0.439 \\
\hline $\begin{array}{l}\text { Morbidly obese } \\
\left(40-49.9 \mathrm{~kg} / \mathrm{m}^{2}\right)\end{array}$ & 0 & - & $1(3.3)$ & $\begin{array}{l}\text { Pulmonary } \\
\text { embolism }\end{array}$ & $3(2.9)$ & $\begin{array}{l}\text { Redo GJ anastomosis + I\&D } \\
\text { abdominal wall abscess; } \\
\text { laparotomy and redo JJ } \\
\text { anastomosis; laparoscopy and } \\
\text { drainage of interloop abscess }\end{array}$ & \\
\hline $\begin{array}{l}\text { Super-obese } \\
\left(50-59.9 \mathrm{~kg} / \mathrm{m}^{2}\right)\end{array}$ & 0 & - & $1(3)$ & $\begin{array}{l}\text { Death: suspected } \\
\text { micro leak from } \\
\text { staple line }\end{array}$ & $1(1)$ & $\begin{array}{l}\text { Laparoscopy and reduction of } \\
\text { internal hernia }\end{array}$ & \\
\hline $\begin{array}{l}\text { Super-super-obese } \\
\left(>60 \mathrm{~kg} / \mathrm{m}^{2}\right)\end{array}$ & 0 & - & 0 & & 0 & & \\
\hline 30-day readmission rate $n$ & (\%): & & & & & & 0.376 \\
\hline Morbidly obese & 0 & - & $1(3.3)$ & & $3(2.9)$ & $\begin{array}{l}\text { Constipation requiring } \\
\text { manual evacuation (2); } \\
\text { diagnostic laparoscopy (1) }\end{array}$ & \\
\hline Super-obese & $1(2.6)$ & $\begin{array}{l}\text { Intractable nausea } \\
\text { and vomiting requir- } \\
\text { ing subsequent } \\
\text { removal of band }\end{array}$ & $1(3)$ & $\begin{array}{l}\text { Death: query } \\
\text { micro leak from } \\
\text { staple line }\end{array}$ & $3(2.9)$ & $\begin{array}{l}\text { Constipation requiring manual } \\
\text { evacuation (1); diagnostic } \\
\text { laparoscopy (1); seroma at } \\
\text { anastomosis managed } \\
\text { conservatively (1) }\end{array}$ & \\
\hline Super-super-obese & 0 & & 0 & & 0 & & \\
\hline
\end{tabular}


Table 5 Secondary outcomes: remission of comorbidities for study participants.

\begin{tabular}{|c|c|c|c|c|}
\hline Comorbidity resolution (end of two years) & LAGB $(n=65)$ & LSG $(n=70)$ & LRYGB $(n=218)$ & $P$-value ${ }^{a}$ \\
\hline \multicolumn{5}{|l|}{ Diabetes $^{\mathrm{b}} n,(\%)$ : } \\
\hline Morbidly obese $\left(40-49.9 \mathrm{~kg} / \mathrm{m}^{2}\right)$ & $3(13.6)$ & $1(3.3)$ & $25(24.3)$ & 0.011 \\
\hline Super-obese $(50-59.9$ kg/m²) & $3(7.9 \%)$ & $2(6.1)$ & $14(15.2)$ & 0.013 \\
\hline Super-super-obese (> 60 kg/m²) & 0 & 0 & $3(23.1 \%)$ & nc \\
\hline \multicolumn{5}{|l|}{ Obstructive sleep apnoea ${ }^{\mathrm{b}} n,(\%)$ : } \\
\hline Morbidly obese & 0 & $4(13.3)$ & $7(6.8)$ & 0.132 \\
\hline Super-obese & $2(5.3)$ & $3(9.1)$ & $10(9.9)$ & 0.014 \\
\hline Super-super-obese & 0 & 0 & 0 & $\mathrm{nc}$ \\
\hline \multicolumn{5}{|l|}{ Hypertension ${ }^{\mathrm{b}} n,(\%)$ : } \\
\hline Morbidly obese & $3(13.6)$ & $1(3.3)$ & $16(15.5)$ & 0.196 \\
\hline Super-obese & $3(7.9)$ & $4(12.1)$ & $7(6.9)$ & 0.964 \\
\hline Super-super-obese & 0 & 0 & 0 & $\mathrm{nc}$ \\
\hline \multicolumn{5}{|l|}{ Dyslipidaemia $^{\mathrm{b}} n,(\%)$ : } \\
\hline Morbidly obese & $3(13.6)$ & $4(13.3)$ & $17(16.5)$ & 0.173 \\
\hline Super-obese & $6(15.8)$ & $3(9.1)$ & $7(6.9)$ & 0.825 \\
\hline Super-super-obese & 0 & 0 & $2(15.4)$ & $\mathrm{nc}$ \\
\hline \multicolumn{5}{|l|}{ Asthma ${ }^{\mathrm{b}} n,(\%):$} \\
\hline Morbidly obese & 0 & $3(10)$ & $3(2.9)$ & 0.383 \\
\hline Super-obese & 0 & 0 & $6(5.9)$ & 0.014 \\
\hline Super-super-obese & 0 & 0 & 0 & $\mathrm{nc}$ \\
\hline \multicolumn{5}{|l|}{ Gastro-oesophageal reflux disease ${ }^{\mathrm{b}} n,(\%)$ : } \\
\hline Morbidly obese & 0 & $1(3.3)$ & $10(9.7)$ & 0.301 \\
\hline Super-obese & $4(10.5)$ & $1(3)$ & $3(3)$ & 0.299 \\
\hline Super-super-obese & 0 & 0 & 0 & $\mathrm{nc}$ \\
\hline \multicolumn{5}{|l|}{ Depression $n,(\%)$ : } \\
\hline Morbidly obese & $2(9.1)$ & $3(10)$ & $3(2.9)$ & 0.054 \\
\hline Super-obese & 0 & $2(6.1)$ & $6(5.9)$ & 0.350 \\
\hline Super-super-obese & 0 & 0 & 0 & $\mathrm{nc}$ \\
\hline \multicolumn{5}{|c|}{ Exercise tolerance (flights of stairs), median (IQR): } \\
\hline Morbidly obese & $3(0.75-3)$ & 3 & 3 & 0.094 \\
\hline Super-obese & $1(0.375-3)$ & $3(0.5-3)$ & 3 & $<0.001$ \\
\hline Super-super-obese & 2 & 2 & $1(0-3)$ & 0.659 \\
\hline
\end{tabular}

different and patients were not self-selected into a particular bariatric procedure, what is evident from both studies is the better results with LRYGB in the higher BMI subcategories without any increase in perioperative morbidity when compared with restrictive procedures. Thus, weight and/or BMI should not be determinants for selection or recommendation of bariatric procedures and in those patients who qualify for all three procedures and wish for the multidisciplinary team to recommend the best procedure, our units default position is to offer LRYGB as the bariatric and metabolic procedure of choice.

This study has also shed some light on the difficult choices with the super-super-obese patients, who carry significant perioperative risk factors and the fear of 
postoperative complications with a relatively more complex bariatric procedure such as the LRYGB has traditionally guided surgeons to offer an interim procedure such as the gastric balloon ${ }^{20}$ or sleeve gastrectomy ${ }^{21}$ to downgrade the patientâs BMI to an acceptable range before offering a more definitive malabsorptive procedure such as the LRYGB when indicated. Opponents of this strategy quote the potential for higher risk with subsequent revisional bariatric procedures and financial consequences with dual procedures. Our results validate this approach of phased treatment in patients who are super-super-obese by demonstrating non-superiority of any of the three standard procedures (LRYGB, LSG and LAGB are generally offered within the NHS). Although our results did not show a significant difference in the perioperative complications in the super-super-obese subgroup with the more complex LRYGB, this may represent a type 2 error with only few patients who are super-super-obese undergoing one of the three procedures compared in the study. When the above results are considered in conjunction with the significantly favourable results seen with LRYGB in the super-obese (BMI 50-59.9 kg/m ${ }^{2}$ ) subgroup, bariatric units could consider adopting guidelines and counsel patients who are super-super-obese towards phased treatment with an interim procedure to achieve a target BMI between $50 \mathrm{~kg} /$ $\mathrm{m}^{2}$ and $59.9 \mathrm{~kg} / \mathrm{m}^{2}$, when a more definitive procedure in the form of LRYGB could be offered to achieve the patient's target excess weight loss and comorbidity resolution. Similar targets could also be discussed with patients who are super-super-obese along the tier 3 weight management pathway to optimise preoperative weight and BMI in order to obtain better results with LRYGB in eligible patients.

The limitations of this study are that the results are extrapolated from a self-selected non-randomised cohort of patients from a single bariatric unit offering a choice of LRYGB, LSG and LAGB to eligible patients within the remit of free treatment offered in the NHS. The process of choosing an intervention by the patients themselves created quasi-randomised groups which were comparable despite no attempt to control any variables between the groups. Thus, our results would be applicable to bariatric services offered in the NHS across the UK and globally where these three bariatric procedures are being offered as standard treatment. Although there were no power or sample size calculations to establish the magnitude of difference in primary and secondary outcomes between interventions, the individual group sizes were not dissimilar to published randomised controlled trials in literature. Our results can be used to calculate sample sizes for setting up future trials. Another moot point is the retrospective subcategorisation of patients according to the severity of obesity in order to compare the effect of the three different bariatric procedures. The purpose of the observational study was to evaluate the outcomes of the procedures and, in the process, investigated the effects of different techniques on increasing severity of obesity. With continuing collection of data, larger numbers in individual subgroups of obesity will facilitate multivariable statistical analysis to gain further meaningful results.

\section{Conclusions}

Predictors of outcomes following bariatric procedures are an important area of research and are of particular interest to funding and commissioning bodies. Our study has been able to shed some light in this context by demonstrating better comparative outcomes with LRYGB in patients who are super-obese and also makes a case for phased treatment strategy for those who are super-super-obese. The above findings may guide practitioners to counsel patients and may pre-empt outcomes based on the degree of obesity and the intervention chosen by the patient.

\section{Acknowledgements}

We would like to especially acknowledge and thank John Finney, bariatric dietitian, and Katie Kirk, bariatric nurse specialist, for their dedication and relentless efforts to achieve seamless patient care. They have been instrumental in collecting and maintaining the departmental's data registry.

\section{References}

1. Colquitt JL, Pickett K, Loveman E, Frampton GK. Surgery for weight loss in adults. Cochrane Database Syst Rev 2014; (8): CD003641.

2. Franco JV, Ruiz PA, Palermo M, Gagner M. A review of studies comparing three laparoscopic procedures in bariatric surgery: sleeve gastrectomy, Roux-en-Y gastric bypass and adjustable gastric banding. Obes Surg 2011; 21(9): $1,458-1,468$.

3. American Diabetes Association. Diabetes care in the hospital: standards of medical care in diabetes 2018. Position Statement 14. Diabetes Care 2018; 41 (Suppl 1): S144-S151.

4. Romero-Corral A, Caples SM, Lopez-Jimenez F, Somers VK. Interactions between obesity and obstructive sleep apnea: implications for treatment. Chest 2010; 137(3): 711-719.

5. Stegenga H, Haines A, Jones K, Wilding J; Guideline Development Group. Identification, assessment, and management of overweight and obesity: summary of updated NICE guidance. BMJ 2014; 349: g6608.

6. Vasas $\mathrm{P}$, Nehemiah $\mathrm{S}$, Hussain $\mathrm{A}$ et al. Influence of patient choice on outcome of bariatric surgery. Obes Surg 2018; 28(2): 483-488.

7. Lee JH, Nguyen QN, Le QA. Comparative effectiveness of 3 bariatric surgery procedures: Roux-en-Y gastric bypass, laparoscopic adjustable gastric band, and sleeve gastrectomy. Surg Obes Relat Dis 2016; 12(5): 997-1,002.

8. Carlin AM, Zeni TM, English WJ et al. The comparative effectiveness of sleeve gastrectomy, gastric bypass, and adjustable gastric banding procedures for the treatment of morbid obesity. Ann Surg 2013; 257(5): 791-797.

9. Chang SH, Stoll CR, Song J et al. The effectiveness and risks of bariatric surgery: an updated systematic review and meta-analysis, 2003-2012. JAMA Surg 2014; 149(3): 275-287.

10. Yang X, Yang G, Wang W et al. A meta-analysis: to compare the clinical results between gastric bypass and sleeve gastrectomy for the obese patients. Obes Surg 2013; 23(7): 1,001-1,010.

11. Rogers CA, Reeves BC, Byrne J et al. Adaptation of the By-Band randomized clinical trial to By-Band-Sleeve to include a new intervention and maintain relevance of the study to practice. Br J Surg 2017; 104(9): 1,207-1,214

12. Fischer $\mathrm{L}$, Wekerle $A \mathrm{~L}$, Bruckner $\mathrm{T}$ et al. BariSurg trial: sleeve gastrectomy versus Roux-en-Y gastric bypass in obese patients with BMI 35-60 kg/m(2): a multi-centre randomized patient and observer blind non-inferiority trial. BMC Surg 2015; 15: 87

13. van de Laar A, de Caluwe L, Dillemans B. Relative outcome measures for bariatric surgery: evidence against excess weight loss and excess body mass index loss from a series of laparoscopic Roux-en-Y gastric bypass patients. Obes Surg 2011; 21(6): 763-767.

14. van de Laar AW, van Rijswijk AS, Kakar $\mathrm{H}$, Bruin SC. Sensitivity and specificity of $50 \%$ excess weight loss ( $50 \% \mathrm{EWL}$ ) and twelve other bariatric criteria for weight loss success. Obes Surg 2018; 28(8): 2,297-2,304. 
15. Varban OA, Cassidy RB, Bonham A et al. Factors associated with achieving a body mass index of less than 30 after bariatric surgery. JAMA Surg 2017; 152 (11): 1,058-1,064

16. Gilhooly DA, Cole M, Moonesinghe SR. The evaluation of risk prediction models in predicting outcomes after bariatric surgery: a prospective observational cohort pilot study. Perioper Med 2018; 7: 6.

17. Krimpuri RD, Yokley JM, Seeholzer EL et al. Qualifying for bariatric surgery: is preoperative weight loss a reliable predictor of postoperative weight loss? Surg Obes Relat Dis 2018; 14(1): 60-64.

18. Eriksson Hogling D, Ryden $M$ et al. Body fat mass and distribution as predictors of metabolic outcome and weight loss after Roux-en-Y gastric bypass. Surg Obes Relat Dis 2018; 14(7): 936-942.
19. Jain D, Sill A, Averbach A. Do patients with higher baseline BMI have improved weight loss with Roux-en-Y gastric bypass versus sleeve gastrectomy? Surg Obes Relat Dis 2018; 14(9): 1,304-1,309.

20. Busetto L, Tregnaghi A, De Marchi F et al. Liver volume and visceral obesity in women with hepatic steatosis undergoing gastric banding. Obes Res 2002; 10 (5): 408-411.

21. Mukherjee S, Devalia K, Rahman MG, Mannur KR. Sleeve gastrectomy as a bridge to a second bariatric procedure in superobese patients: a single institution experience. Surg Obes Relat Dis 2012; 8(2): 140-144. 